Tellus A Dynamic Meteorology and Oceanography January 2010, Volume 62 Issue 1, Pages 80 - 90 http://dx.doi.org/10.1111/i.1600-0870.2009.00418.x (c) 2009 Wiley Blackwell Publishing, Inc.
Archimer, archive institutionnelle de l'fremer http://www.ifremer.fr/docelec/

\title{
Cessation and partial reversal of deep water freshening in the northern North Atlantic: observation-based estimates and attribution
}

\author{
Artem Sarafanov ${ }^{1,{ }^{\star}}$, Herlé Mercier ${ }^{2}$, Anastasia Falina $^{1}$, Alexey Sokov $^{1}$ and Pascale Lherminier ${ }^{2}$ \\ ${ }^{1}$ P.P. Shirshov Institute of Oceanology, 36, Nakhimovskiy Prospect, 117997 Moscow, Russia \\ ${ }^{2}$ Laboratoire de Physique des Océans, Ifremer, UMR 6523 CNRS/IFREMER/IRD/UBO, Plouzané, France \\ *: Corresponding author : Artem Sarafanov, email address : sarafanov@mail.ru
}

\begin{abstract}
:
Recent decadal salinity changes in the Greenland-Scotland overflow-derived deep waters are quantified using CTD data from repeated hydrographic sections in the Irminger Sea. The Denmark Strait Overflow Water salinity record shows the absence of any net change over the 1980s-2000s; changes in the Iceland-Scotland Overflow Water (ISOW) and in the deep water column $\left(\sigma_{0}>27.82\right)$, enclosing both overflows, show a distinct freshening reversal in the early 2000s. The observed freshening reversal is a lagged consequence of the persistent ISOW salinification that occurred upstream, in the Iceland Basin, after 1996 in response to salinification of the northeast Atlantic waters entrained into the overflow. The entrainment salinity increase is explained by the earlier documented North Atlantic Oscillation (NAO)-induced contraction of the subpolar gyre and corresponding northwestward advance of subtropical waters that followed the NAO decline in the mid-1990s and continued through the mid-2000s. Remarkably, the ISOW freshening reversal is not associated with changes in the overflow water salinity. This suggests that changes in the NAO-dependent relative contributions of subpolar and subtropical waters to the entrainment south of the Iceland-Scotland Ridge may dominate over changes in the Nordic Seas freshwater balance with respect to their effect on the ISOW salinity.
\end{abstract}




\section{Introduction}

Nordic Seas overflow-derived deep waters in the subpolar North Atlantic - the Denmark Strait Overflow Water (DSOW) and Iceland-Scotland Overflow Water (ISOW) - freshened during the last decades of the 20th century (Dickson et al., 2002, hereinafter referred to as D02). The 1965-2000 freshening rates, derived from the regression analysis of the salinity time series in the Labrador and Irminger Seas and Iceland Basin, are 0.013-0.015 and 0.008-0.013 per decade for DSOW and ISOW, respectively (D02).

Though both water masses rapidly freshened at similar rates, features of their salinity changes were different: unlike ISOW, the DSOW salinity substantially varied from year to year. Particularly strong interannual variability of DSOW salinity (up to $\sim 0.03$ per year) was observed in the $1990 \mathrm{~s}$ in the Irminger Sea (D02, their Figure 2), where DSOW is not yet strongly modified by along-path mixing with ISOW. Given the strong interannual signal, the DSOW freshening in the Irminger Sea between 1965 and 2000 may not be best described by a simple linear trend: several episodes of sign changes in salinity (S) tendency (i.e., $\partial S / \partial t$ ) are evident alongside the apparent strong freshening between the late 1960s and early 1980s. Similarly, the ISOW freshening in the Iceland Basin, i.e. nearby the source region for this water mass, has been ascribed to the same period (1965-2000), despite a distinct ISOW salinification in the second half of the 1990s (D02, their Figure 2).

More recent analysis of the data from repeated hydrographic observations in the subpolar North Atlantic has shown the nearly steady salinification of ISOW east of the Reykjanes Ridge since 1996-1997 (Sarafanov et al., 2007, hereinafter referred to as S07) and the arrival of the ISOW salinification signal into the Irminger Sea (S07) and Labrador Sea (Yashayaev and Dickson, 2008) at the beginning of the 2000s. However, the reported ISOW freshening reversal has not been explained; and the recent decadal trends in the DSOW properties have not been assessed.

In this paper, we use CTD data from repeated hydrographic sections in the southern Irminger Sea (Figure 1, section 2), were both overflow-derived deep water masses are observed (e.g., S07, their Figure 1), to quantify thermohaline changes in the DSOW and ISOW layers in 1991-2007. We 
reconstruct temperature and salinity records for the entire deep water column and assess the recent decadal changes in the overflow-derived deep water properties (section 3). We also examine the long-term signal in the DSOW salinity record, using the 1963-2001 time series (D02) updated with recent observations (section 4). Finally, we propose an explanation for the observed salinity change in the deep water stratum (section 5).

Importance of the issue is emphasized by the fact that researchers are currently far from reaching a consensus in understanding the nature of the deep-water property anomalies in the subpolar gyre on a decadal time scale.

The overflow water freshening has been commonly attributed to an increase in freshwater input to the Nordic Seas due to increasing net precipitation at high latitudes, ice melting and increasing river discharge to the Arctic (see Curry et al., 2003; Peterson et al., 2006). Alternatively, according to the most recent results of the model study by Scheinert et al. (2008), decadal salinity changes at the deep levels in the subpolar North Atlantic can be explained by the North Atlantic Oscillation (NAO)-dependent variability of the freshwater exchange between the subpolar and subtropical gyres, while changes in the surface fluxes and freshwater export from the Arctic are of a minor importance.

Since one of the common ways to investigate the mechanisms behind the deep-water temperature and salinity anomalies is an analysis of model simulations, which have to reproduce the observed tendency changes in the water mass properties, quantitative information on these changes, derived from the observations, is important. Furthermore, as we show below, some of the basic mechanisms responsible for the multiyear changes in the deep water properties can be deduced from the observed property changes of the water masses contributing to the deep water formation. Finally, observations of the overflow water properties in the high latitude North Atlantic have been recently asserted to be crucial for predictability of long-term changes in the Atlantic meridional overturning circulation (Hawkins and Sutton, 2008). 


\section{Data and method}

To quantify changes in the deep water temperature and salinity since the early 1990s we used the CTD data from the seven occupations of the WOCE A1E/AR7E line (1991-1997) (Bersch, 2002), five repeats of the $60^{\circ} \mathrm{N}$ transatlantic section (2002-2007) (Falina et al., 2007; S07; Sokov, 2007) and the section carried out by the Dutch RV Pelagia (2000) (van Aken, 2000). Section locations are shown in Figure 1. The accuracy of the temperature and salinity data is better than $0.003^{\circ} \mathrm{C}$ and 0.003 , respectively.

For the nearly co-located western parts of the sections (west of the Reykjanes Ridge), the mean values of salinity and potential temperature $(\theta)$ were calculated for the deep water layer, enclosing both overflows, and for the DSOW and ISOW layers separately. When computing the mean values, the CTD S and $\theta$ were weighted with the distances between the stations.

The water mass layers were defined with the following density limits earlier used by S07: $\sigma_{0}>27.90$ for DSOW, $27.82<\sigma_{0}<27.86$ for ISOW and $\sigma_{0}>27.82$ for the whole deep water column including DSOW, ISOW and their mixture in between $\left(27.86<\sigma_{0}<27.90\right)$. During the 2005 occupation of the $60^{\circ} \mathrm{N}$ section, two stations in the eastern part of the Irminger Sea, where the deep salinity maximum associated with ISOW stands out, were missed due to storm conditions; therefore, the 2005 data were used for calculation of the DSOW layer properties only. The layeraveraged $\theta$ and $S$ values are shown in the form of anomalies relative to the 1991-2007 means in Figure 2.

Though the features of thermohaline changes in the DSOW and ISOW layers are different (as we show below), quantification of changes in the deep water column $\left(\sigma_{0}>27.82\right)$ as a whole is important from a large-scale perspective. Indeed, DSOW and ISOW (together with the Labrador Sea Water (LSW) whose recent $\theta-S$ changes have been thoroughly discussed elsewhere (Falina et al., 2007; S07; Yashayaev et al., 2007; 2008)) contribute to the formation of the North Atlantic Deep Water constituting the lower limb of the global overturning circulation and thus contributing to the Earth's heat and freshwater cycle. 
106

\section{Overflow-derived water property changes, 1991-2007}

The time series of the DSOW salinity and potential temperature anomalies (Figure 2a and 2b) show a strong interannual variability ( $\mathrm{S}$ standard deviation is 0.014 ), but no significant trend can be detected between 1991 and 2007. Thus, including the mid-2000s in the analysis discards any significant net change in the DSOW properties over the last 16 years.

The ISOW property time series (Figures $2 \mathrm{c}$ and $2 \mathrm{~d}$ ) are less affected by interannual variability and clearly show cooling and freshening in the 1990s and reversal of this trend in 2002 . Over the five years after 2002 , the ISOW $\theta$ and $\mathrm{S}$ increased by $0.16^{\circ} \mathrm{C}$ and 0.020 , respectively.

The difference between the ISOW salinity interannual variability and that of DSOW (relative to a long-term signal) can be quantified via inspection of mean regression residuals. For ISOW, the 3rd-order polynomial accounts for most of variance $\left(\sim 93 \%, \mathrm{R}^{2} \approx 0.93\right.$, see Figure 2 caption for the $\mathrm{R}^{2}$ definition) in the ISOW salinity record (Figure $2 \mathrm{c}$ ), and the mean absolute difference between the actual and regression salinities is 0.0028 . For DSOW, the mean deviations of the observed salinities from the 1st-, 2nd- and 3rd-order regressions (0.011-0.014, depending on regression degree) do not considerably differ from the standard deviation of the time series (0.014) being 4-5 times larger than for ISOW (0.0028). Thus, interannual variability of salinity in the DSOW layer at $60^{\circ} \mathrm{N}$ in $1991-2007$ was $4-5$ times stronger than in the ISOW layer.

The $\theta-\mathrm{S}$ changes in the entire deep water column $\left(\sigma_{0}>27.82\right.$, Figures $2 \mathrm{e}$ and $\left.2 \mathrm{f}\right)$ are determined mostly by the changes in the ISOW layer as the latter is substantially thicker than the DSOW one, see e.g. (S07, their Figure 1). On average for the 1991-2007 period, the volumes of the ISOW and DSOW layers, as they are defined in the study, equal, respectively, $\sim 60 \%$ and $\sim 10 \%$ of the volume of the whole deep water column in the sections (the remaining $\sim 30 \%$ are accounted for by the ISOW-DSOW mixture), and this ratio is nearly constant on a decadal time scale. Figure 3 shows that the mean salinity in the deep water column highly correlates with the ISOW salinity $\left(R^{2}=0.96, p<0.001\right)$, while its correlation with the DSOW salinity is much weaker $\left(R^{2}=0.30\right.$, $\mathrm{p} \approx 0.34$ ); same applies to $\theta$ (no figure shown). 
The mean $\theta$ and $S$ in the deep water layer decreased through the early 2000 s and have been

133 increasing since then owing mostly to the warming and salinification of ISOW. From 2002 to 2007,

134 the deep water column became $0.20^{\circ} \mathrm{C}$ warmer and 0.025 saltier. Although the $\theta$ and $\mathrm{S}$ of the deep

135 water stratum in the Irminger Sea have not yet reached values typical of 1991-1992, the recent

136 warming and salinification were strong enough to compensate for the most part of the cooling and

137 freshening in the 1990s, resulting in nearly zero trends over the last one and a half decade (1992138 2007).

In addition to the time series of the layer-averaged temperature and salinity values, in

Figure 4 we show the vertical structure of the 1991-2007 salinity changes on isopycnal surfaces in the deep water column in the Irminger Sea interior $\left(36-39^{\circ} \mathrm{W}\right)$, where the deep salinity maximum associated with ISOW is most pronounced and thus the signal of the ISOW salinity changes is most clear.

Besides the distinct freshening reversal in the early 2000s, the most interesting feature in Figure $4 \mathrm{~b}$ is a non-uniform timing of salinity changes within the ISOW layer. Thus, at the upper ISOW density levels (27.82-27.83), the lowest salinity values were observed in 2000; at the ISOW core density level (27.84) salinity reached a minimum in 2000-2002 (salinity values in 2000 does not differ significantly from those in 2002), while in the lower part of the ISOW layer (27.8527.86) the minimum salinity was observed in 2002. In other words, in the upper part of the ISOW layer the long-term freshening reversed $~ 1-2$ years earlier than in its lower part.

The only apparent cause of this shift is the influence of salinity change in the overlying LSW layer. The cold and fresh deep LSW $\left(27.76<\sigma_{0}<27.81\right)$ formed by very deep convection in the

153 Labrador Sea (Lazier et al., 2002) and likely in the Irminger Sea (Pickart et al., 2003; Falina et al., 154 2007) in anomalously severe winters in the first half of the 1990s has not been renewed since then 155 (at least prior to the winter of 2007-2008 (Yashayaev and Loder, 2009; Våge et al., 2009)) and has 156 been gradually warming and salinifying in the subpolar North Atlantic in the past decade 157 (Yashayaev et al., 2007; 2008). Figure 4b shows that in the lower part of the LSW layer (27.79- 
27.80) salinity reached its minimum in 1995-1996 and has been monotonically increasing since then. A transfer of the LSW salinification signal to deeper levels via mixing, see (Yashayaev et al., 2008), explains the detected $~ 1-2$-year shift in the beginning of salinification between the upper and lower parts of the ISOW layer. Note that an along-path mixing of ISOW with salinifying LSW is not the main cause of the recent ISOW salinification (as we discuss in section 5) but this mixing appears to be the factor amplifying the salinity increase at least in the upper part of the ISOW layer along the ISOW pathway.

A transfer of salinity signals carried by LSW from its source region throughout the subpolar gyre to deeper levels has been previously inferred by Yashayaev et al. $(2007 ; 2008)$ and Yashayaev and Dickson (2008) from volumetric analysis of the AR7W line dataset and from comparison of timing of the ISOW and LSW salinity changes in different subpolar basins. The shift in timing of the recent freshening reversal in the upper and lower parts of the ISOW layer, seen in Figure 4b, is another evidence for the diapycnal transfer of the LSW salinity signal to ISOW.

Figure 4 also shows a more complicated distribution of salinity anomalies below the ISOW layer $\left(\sigma_{0}>27.86\right)$. This structure is clearly associated with the DSOW variability that thus strongly affects the pattern of salinity changes at the density levels of the ISOW-DSOW mixture (27.8627.90).

Although the main features of the DSOW variability are reflected in Figure 4, the figure is not entirely representative for the DSOW layer as a whole due to a substantial zonal heterogeneity of the latter in some years. For instance, the DSOW layer on average was freshest in 2004 (Figure 2a), while the minimum near-bottom salinities in the Irminger Sea interior were observed in 2002 (Figure 4). This is due to the fact that an extremely fresh fraction of the DSOW flow in 2004 was found at the Greenland slope east of $39^{\circ} \mathrm{W}$ (at depths of 2200-2500 m), see (Falina et al. 2007, their Figure 4), and thus the lowest DSOW salinities in 2004 were outside of the longitude range $\left(36-39^{\circ} \mathrm{W}\right)$ chosen to capture the clearest ISOW salinity signal. 
183

\section{On the long-term changes in the DSOW salinity, 1963-2007}

The main difficulty in detecting a decadal signal in the DSOW properties arises from their strong short-term variability. The 1991-2007 time series show that in the Irminger Sea variability of the DSOW salinity is $4-5$ times stronger than that of ISOW. For ISOW, the long-term signal is distinct and allows us to claim a freshening reversal at the beginning of the 21 st century, while all we can determine from the 1991-2007 time series for DSOW is the absence of net property change over the considered time period.

To consider the DSOW salinity changes from a longer-term perspective, we have incorporated the newly obtained salinity values into the historical record. Figure 5a shows the 44year-long time series of the DSOW salinity anomalies derived from a compilation of the salinity values reported by D02 for the western Irminger Sea domain (1963-2001, 'WIS' DSOW in their Figure 2) and the DSOW salinities from the present study (2002-2007). We have examined compatibility of the two time series via a comparison of the salinity values for their overlapping parts (1991-2000). Figure 5b shows that the salinity values from D02 and those derived in this study are very close to each other. The mean absolute difference between the two time series is 0.002 that does not exceed a typical accuracy of salinity measurements $( \pm 0.002)$, being an order of magnitude less than the standard deviation (0.023) for the 1963-2007 time period. In other words, this difference is very small relative to the scale of the DSOW salinity changes and thus is not critical at least for assessment of decadal trends in the record.

The DSOW freshening is evident from Figure 5a for the 1969-1983 time period. The post1983 part of the salinity record shows strong variability, and the 1983-2007 salinity changes compensate each other resulting in the nearly zero trend $(+0.002 /$ decade, indistinguishable from zero at the $90 \%$ confidence level). Thus, the updated DSOW salinity anomaly record for the Irminger Sea does not reveal any net change in the DSOW salinity over the past two and a half decades. 


\section{Attribution of the observed reversal of deep water freshening}

The strong short-term variability of the DSOW salinity was recently attributed to changes in

210 the local wind forcing over the Denmark Strait (Holfort and Albrecht, 2007). Wind strength

211 variations affect the contribution of fresher/saltier water masses of northern/southern origin to the

212 DSOW formation and thus result in substantial DSOW salinity variations on time scales from

213 months to several years. The researchers note, however, that this mechanism does not explain 214 decadal changes, in particular, the freshening of DSOW. Currently, we cannot provide an 215 explanation for the complicated pattern of decadal changes in the DSOW properties shown herein, 216 to some extent because the decadal signal-to-noise ratio is too low. The DSOW salinity drop (217 0.06) in the 1970 s - early 1980s represents the only distinct persistent decadal trend in the record 218 (Figure 5a) and could be very well described even by a linear fit $\left(\mathrm{R}^{2}=0.92\right)$. For the following 219 decades, no distinct decadal signal can be detected with certainty: all the applied polynomial models 220 account for less than a half of DSOW salinity variance for the post-1983 part of the record (e.g., 221 Figure 2a).

However, as shown in section 3, the 1991-2007 changes in the average properties of the entire deep water column $\left(\sigma_{0}>27.82\right)$ in the Irminger Sea are determined mostly by changes in the ISOW layer. The contribution of DSOW variability is barely significant, and no significant trend in the recent DSOW salinity changes is detected. So, despite the strong DSOW variability that is different from that of ISOW, the long-term changes in the deep water column properties during the last two and a half decades, including the recent freshening reversal, can be attributed primarily to the multiyear changes in the ISOW layer.

\subsection{Why did the ISOW salinity trend change its sign?}

The ISOW salinity increase observed in the Irminger Sea since the early 2000s is a lagged 
2331996 and salinified over the following decade, see (S07). From 1997 to 2006, salinity in the ISOW 234 core in the Iceland Basin persistently increased by 0.022 (S07); on average for the ISOW layer $235\left(\sigma_{0}>27.86\right)$ in 1997-2007, salinity increased by 0.016 (Figure 6).

The ISOW properties in the Iceland Basin result from mixing of intermediate and deep waters, convectively formed in the Nordic Seas and entering the North Atlantic over the IcelandScotland Ridge, with the overlying warm saline Atlantic waters (hereinafter the 'entrainment') and the Labrador Sea Water (LSW) (Aken and de Boer, 1995; D02; Fogelqvist et al., 2003; Eldevik et al., 2009). According to D02, approximate relative contributions of these three components to ISOW at the eastern slope of the Reykjanes Ridge are $43 \%$ for the Faroe-Shetland overflow water, $31 \%$ for the entrainment (defined in that study as the 500-1000 m layer in the northern Iceland Basin) and $26 \%$ for LSW.

All three components non-steadily freshened since the mid-1960s - early 1970s resulting in a persistent long-term freshening of their mixture, the ISOW (see D02, their Figure 3). The abrupt reversal of the ISOW freshening in 1996-1997 implies the concurrent salinification of at least one of the ISOW source components in suggestion that their relative contributions to ISOW did not change considerably in the mid-1990s.

In Figure 7, we examine the time series of salinity anomalies for (i) the ISOW source components as measured in the Iceland Basin (overflow, entrainment and LSW) normalized with respect to their relative contribution to ISOW according to D02 (Figures 7a-7c), (ii) their 'mixture' calculated by summing algebraically the normalized salinity anomalies for the three individual components following the recipe of D02 (Figure 7d) and (iii) ISOW observed at the eastern flank of the Reykjanes Ridge (Figure 7e). Anomalies are given for the 1981-2001 time period, for which the data on salinity changes of all three components are available, and which includes the long-term freshening of these waters, the ISOW freshening reversal in 1996-1997 and the beginning of the ISOW salinification in subsequent years. 
In order to examine the contribution of salinity changes in the ISOW components to the

ISOW freshening reversal in the 1990s we plotted, in the right panels of Figure 7, the salinity anomalies for each component and their combinations versus the ISOW salinity anomalies for the 1990-2000 decade and assessed their correlation. Since there is no significant trend in the ISOW salinity $(<+0.0001 /$ decade $)$ in the Iceland Basin for the decade considered, the correlations shown in Figures $7 \mathrm{f}-7 \mathrm{j}$ are not biased by any long-term trends, being thus representative for the 'ISOW ISOW component' relations in salinity on an inter-annual time scale.

Figure 7a shows no freshening reversal for the Faroe-Shetland overflow at least prior to 1999, and therefore this origin for the ISOW freshening reversal in 1996-1997 can be instantly excluded. Furthermore, the magnitudes of the overflow salinity changes in the 1990s (Figure 7a) are less than those required to explain the ISOW salinity changes (Figure 7e), and the correlation between the overflow and ISOW salinity anomalies is very weak $(\mathrm{R}=0.14)$ being significant only at the 0.28 confidence level (Figure 7f).

Freshening of LSW reversed in its main source region, the Labrador Sea, in the mid-1990s (1994-1995) due to weakening of deep convection (Lazier et al., 2002); a sustained salinification in the LSW stratum followed (e.g., Yashayaev et al., 2007). Salinification of LSW most likely amplified the ISOW salinification (as discussed in section 3), but it could not be responsible for the ISOW freshening reversal in the Iceland Basin in 1996-1997 as the spreading time for LSW from the Labrador Sea to the Iceland Basin is $~ 5$ years (Yashayaev et al., 2007). Indeed, Figure 7b shows that LSW in the Iceland Basin reached its freshest state in 1999 and the signal of LSW salinification arrived to the Basin in 2000 that is 3-4 years after the ISOW freshening reversal. Furthermore, similarly to the overflow water case, magnitudes of the LSW salinity changes themselves cannot explain those of ISOW in the 1990s, and the LSW - ISOW salinity anomaly correlation for the decade is weak $(\mathrm{R}=0.38)$ being significant only at the 0.69 level.

Not surprisingly, time series of the sum of the overflow and LSW salinity anomalies shows no salinity increase prior to 1999-2000 (no figure shown), and the correlation between the 
284 'overflow + LSW mixture' and the ISOW salinity anomalies is weak $(\mathrm{R}=0.32)$ and insignificant $285(\mathrm{p}=0.44)$, see Figure $7 \mathrm{j}$.

Hence, only the Atlantic waters entrained into the Iceland-Scotland overflow can possibly be responsible for the ISOW freshening reversal. The time series of salinity anomalies for the entrainment (Figure 7c) supports this idea: the long-term freshening of the entrainment reversed in 1994-1996. From 1996 to $1999-2000$, its salinity increased by $\sim 0.05$ that is $\sim 3.5$ times more than the 1996-2000 ISOW salinity increase (0.014, Figure 7e). Given the $\sim 30 \%$ entrainment fraction in ISOW, the net ISOW salinification in the Iceland Basin in 1996-2000 can be explained by salinification of the entrainment. The correlation between the entrainment and ISOW salinity anomalies for the $1990 \mathrm{~s}(\mathrm{R}=0.72$, significant at the 0.98 level $)$ is substantially higher than the overflow - ISOW and LSW - ISOW salinity anomaly correlations (Figure 7h).

Thus, we conclude that the major cause of the ISOW freshening reversal in the Iceland Basin in the 1990s was the increase in the entrained water salinity.

Although the overflow and LSW salinity variations are not responsible for the change of the ISOW salinity trend sign, these variations contributed to the ISOW salinity changes in the 1990s to some extent. Indeed, the 'overflow + LSW + entrainment mixture' - ISOW salinity anomaly correlation $(R=0.79$, significant at the 0.98 level, Figure $7 i)$ is slightly higher than the correlation between the entrainment and ISOW salinity anomalies $(\mathrm{R}=0.72)$. In other words, salinity anomalies for the three water types, contributing to the ISOW formation, correlate with the observed ISOW salinity anomalies more closely when summed than they do separately. The 'mixture' - ISOW salinity correlation for the 1990s is not perfect but high $(\mathrm{R}=0.79)$, suggesting that representation of ISOW as a mixture of the three water types according to the recipe of D02 is somewhat simplified but generally suitable.

Our conclusion on the primary role of the entrainment salinity change in the ISOW 308 freshening reversal agrees with the suggestion by Yashayaev and Dickson (2008) that the deep water salinity increase detected in the Labrador Sea in the first half of the 2000s resulted from a 
310 remote effect of salinification of the Subpolar Mode Water (SPMW), entrained into the ISOW layer

311 along the Reykjanes Ridge, rather than from the influence of salinification in the LSW layer.

\subsection{On the cause of salinification of Atlantic waters entrained into ISOW}

What remains to be explained to complete the attribution of the recent deep water freshening reversal is the cause of reversal of the long-term freshening of the northeast Atlantic waters, entrained into ISOW, in the mid-1990s.

As has been discussed in a number of studies (Bersch, 2002; Hátún et al., 2005; Bersch et al., 2007; Holliday et al., 2008; Thierry et al., 2008; Sarafanov et al., 2008; Sarafanov, 2009; Häkkinen and Rhines, 2009), substantial salinification of the upper-ocean and upper intermediate waters throughout the eastern subpolar North Atlantic since the mid-1990s occurred due to the northward advance of subtropical waters associated with the NAO-induced slowdown and contraction of the subpolar gyre. The northwestward displacement of the subpolar front started within 1-2 years after the NAO drop in the winter of 1995-1996 (see Bersch et al., 2007; Hátún et al., 2005) and continued through 2005 (Sarafanov et al., 2008). Redistribution of subpolar and subtropical waters caused by the regional scale circulation change resulted in intense salinity and temperature increase in the northeast Atlantic reaching depths of up to 1200 m (e.g., Bersch 2002; Sarafanov et al., 2008) and thus affecting the bulk of waters potentially entrained into ISOW.

In particular, Thierry et al. (2008) reported an intense salinification of SPMW above the eastern flank of the Reykjanes Ridge during nearly a decade after 1995 (by $~ 0.07$ between 1995 and 2006, see their Figure 7) and attributed the SPMW salinification to the NAO-driven redistribution of the subpolar and subtropical waters in the Iceland basin. their Figure 3) of the upper intermediate waters $\left(27.45<\sigma_{0}<27.65\right.$, depths of $\left.\sim 500-1200 \mathrm{~m}\right)$, designated 'IW' ('Intermediate Water') after van Aken and de Boer (1995), in the eastern part of the $60^{\circ} \mathrm{N}$ transatlantic section between $25^{\circ} \mathrm{W}$ and the European slope during the 1997-2005 time 
335 period. They attributed up to two thirds of the derived positive salinity trend to the NAO-induced

336 increase in the subtropical water fraction at that latitude. Waters propagating northward at the IW 337 levels contribute very likely to the entrainment into ISOW, since both the overlying mode waters $338\left(\sigma_{0}<27.4\right)$ and underlying LSW $\left(\sigma_{0}>27.7\right)$ (see Sarafanov et al. 2008, their Figure 2) mix into the 339 ISOW layer.

If we tentatively apply the 0.3 factor (corresponding to the approximate entrainment share in ISOW, see above) to the characteristic magnitude $(+0.06-+0.07)$ of the salinity increase at the IWSPMW levels between the mid-1990s and mid-2000s (Thierry et al. 2008; Sarafanov et al. 2008), then the normalized salinity changes in the IW-SPMW stratum $(+0.018-+0.021)$ appear to be close in magnitude to the post-1997 salinity change in the ISOW layer in the Iceland Basin $(+0.016$, Figure 6).

These estimates suggest that salinification at the SPMW and upper intermediate levels $\left(\sigma_{0}<27.65\right)$ in the northeast Atlantic was strong enough to maintain the ISOW salinity increase in the mid-1990s - mid-2000s, and this, in turn, implies a strong effect of the NAO-induced redistribution of saline (subtropical) and fresh (subpolar) waters in the region on the formation of deep water salinity anomalies.

\subsection{On a link between the deep water freshening reversal and the NAO}

To examine the contribution of the NAO-related surface forcing to the reversal of the entrainment and ISOW freshening in the mid-1990s, we have checked the link between the observed salinity anomalies and the winter NAO index. Figure 8 shows that correlations between the NAO index and the entrainment and ISOW salinity anomalies are strong for the considered decade. The best correlation $(R=-0.84$, for the entrainment salinity anomalies; $R=-0.81$ for those of ISOW, both are significant at the 0.99 level) is achieved with the NAO index averaged for the 6

358 (for the entrainment) and 8 (for ISOW) winters preceding the salinity measurements. This implies a 359 lagged response of water mass properties to the low-frequency changes in the NAO-related 
atmospheric forcing rather than an instant response to the year-to-year atmospheric variability in agreement with the lagged baroclinic response of the subpolar gyre circulation to the NAO-related changes in the surface heat (density) fluxes inferred from model experiments (Gulev et al., 2003).

\section{Summary and discussion}

The analysis of the CTD data from hydrographic sections, repeatedly occupied in the southern Irminger Sea in 1991-2007, shows that the long-term freshening of the GreenlandScotland overflow-derived deep waters ceased and partially reversed in the past decade. Substantial fluctuations of temperature and salinity of DSOW did not result in any significant net changes over the considered time period. Historical record being updated with the post-2001 salinity values shows the absence of any net trend in the DSOW salinity changes in the Irminger Sea over the past two and a half decades.

More sustained salinity (and temperature) changes in the ISOW layer and in the entire deep water column, enclosing both overflows, show reversal of freshening (and cooling) trends in the early 2000s. From 2002 to 2007, the whole deep water column in the Irminger Sea persistently warmed by $0.20^{\circ} \mathrm{C}$ and salinified by 0.025 . The $1991-2007 \theta-\mathrm{S}$ changes in the deep water column occurred primarily due to relatively sustained changes in the ISOW layer, while the contribution of the DSOW variability was far less.

The ISOW salinification in the Irminger Sea resulted from the reversal of the ISOW longterm freshening upstream in the Iceland Basin that occurred in 1996-1997 in response to the NAOinduced contraction of the subpolar gyre and corresponding northwestward advance of saline subtropical waters contributing to the warm entrainment into the overflow layer. Consequently, the gyre circulation changes induced by NAO-related atmospheric forcing appears to be one of the major factors controlling the deep water $\theta-\mathrm{S}$ anomaly formation, and the northeast North Atlantic is thus one of the regions in the world ocean where the fast transfer of the upper-ocean changes to the deep ocean takes place. 
Note that given the large amplitude of short-term variability of the DSOW salinity (Holfort and Albrecht, 2007), the rapid salinification of this water in the recent years (2004-2007, Figure 2a, 4 and 7) cannot be unequivocally attributed to the NAO-induced northward advance of subtropical waters, even though, similarly to ISOW, DSOW entrains a lot of Atlantic waters prior to reach the southern Irminger Sea (e.g., Yashayaev and Dickson, 2008). Future long-term measurements will show whether the recent DSOW salinity increase was solely due to the short-term variability or this salinification reflects a longer-term change. In 2008 , according to the just processed $60^{\circ} \mathrm{N}$ data, DSOW was the most saline (+0.011 relative to the 1963-2007 mean) for the last 30 years (19782008).

The revealed dominant effect of the entrainment salinity change on that of ISOW in the 1990s represents a factor internal to the North Atlantic, while the 1960s-1990s freshening of deep waters has been attributed mostly to a combination of external factors, namely, increasing ice melt, net precipitation at high latitudes and river discharge to the Arctic Ocean (e.g., Peterson et al., 2006). The observations of the deep water properties in the Irminger Sea and Iceland Basin show, however, that despite a persistent increase in freshwater input to the Arctic Ocean and Nordic Seas 400 during the 1970s-1990s, (i) no overall freshening of DSOW is found for the 1.5-2.5 last decades 401 and, what is more remarkable, (ii) ISOW freshening had rapidly reversed in 1996-1997 following a 402 weakening of the NAO-related surface forcing that resulted in a well-documented redistribution of 403 subpolar and subtropical waters in the eastern subpolar North Atlantic. This means that 'internal' 404 factors of the deep-water property changes in the northern North Atlantic may dominate over the 405 'external' ones, as shown herein for the 1990s.

406 From a large-scale perspective, salinity of the overflow-derived deep waters is set by 407 interplay of fresh water advection from the Arctic and saline water advection from the subtropics to 408 the subpolar basins and Nordic Seas. Given a drastic property contrast between these two water 409 types, changes in their relative contribution to the northeast Atlantic and Nordic Seas freshwater 410 balance (see Hátún et al., 2005) seem to be a more important mechanism behind the formation of 
411 deep-water salinity anomalies than individual changes in these two water type properties. Results of 412 the present study imply that the NAO-induced changes in the zonal extension of the subpolar gyre 413 control relative inputs of waters of northern and southern origin to the deep water via changes in 414 their contribution to the northeast Atlantic waters entrained into the deep water flow. Atlantic is the deep convection in the Labrador Sea (e.g., Yashayaev et al., 2008) and likely in the Irminger Sea (Pickart et al., 2003; Falina et al., 2007). During high-NAO winters, intense deep convection overturns large volumes of relatively fresh surface waters thus decreasing salinity in the subpolar basins at the intermediate depths. Weakening of deep convection, as occurred during the neutral-to-low NAO period in the mid-1990s - mid-2000s, results in salinity increase at the LSW levels throughout the subpolar gyre owing to isopycnal mixing of LSW with more saline intermediate waters originating in the northeast Atlantic (see Yashayaev et al., 2007). Diapycnal mixing of LSW with ISOW along the deep water pathway through the subpolar basins modulates salinity signals carried by ISOW from its origin in the northern Iceland basin thus transferring NAO-induced salinity changes from the intermediate depths into the deep ocean.

The observation-based results of the present study add to the growing body of evidence (e.g., Lozier and Stewart 2008; Lozier et al., 2008; Scheinert et al., 2008; Sarafanov, 2009) that the NAOrelated factors including the two factors specified above - the subpolar gyre zonal extension and deep convection intensity - are likely to account for the most part of the thermohaline variability in the water column in the northern North Atlantic on a decadal time scale (1950s-2000s). Thus, 431 according to the recent model study (Scheinert et al., 2008) of decadal changes in freshwater and 432 heat content in the region, including a prominent freshening between the 1960s and 1990s, "the 433 largest contribution to the integral changes in the subpolar North Atlantic has been due to the 434 freshwater and heat exchanges with the subtropical gyre; in contrast to previous suggestions, it 435 indicates <...> a secondary contribution to the subpolar North Atlantic freshwater changes by 436 freshwater export from the Arctic". The authors note that "variability in the subtropical-subpolar 
437 fluxes can be understood in terms of the response of the gyre circulation to atmospheric forcing 438 variability associated with the NAO”.

439 Although some aspects of the recent change in the deep-water freshening trend are considered 440 herein, many interrelated issues regarding the deep-water property anomalies remain to be 441 investigated. What causes the complicated pattern of decadal changes in the DSOW layer; to what 442 extent and at what time lags are the entrainment property changes and the resulting deep-water $\theta-\mathrm{S}$ 443 anomalies linked to the actual NAO-related surface forcing (heat flux and wind stress curl) 444 variations in the subpolar and mid-latitude North Atlantic; what anomalies of the meridional heat 445 and freshwater transport are associated with the observed decadal changes in the deep water 446 properties? We suggest that ongoing monitoring of the overflow-derived deep waters and the upper447 ocean and intermediate waters contributing to the deep water formation is an indispensable source 448 of data to address these issues. 


\section{Acknowledgements}

450 We thank all who contributed to the data acquiring and processing, particularly, Sergey Gladyshev. 451 Our special thanks to Hendrik M. van Aken for the data obtained on board the RV Pelagia in 2000. 452 The two anonymous reviewers are gratefully acknowledged for their constructive comments that 453 helped to improve the manuscript. This study was supported by the Russian Ministry of Education 454 and Science under the "World Ocean" Federal Programme (contract 01.420.1.2.0001), the Russian 455 Foundation for Basic Research (grant 08-05-00858) and the Russian President grant MK456 1998.2008.5. HM is supported by the French National Center for Scientific Research (CNRS) and 457 PL by the French Institute for Marine Science (Ifremer). 


\section{References}

Bersch, M., 2002. North Atlantic Oscillation - induced changes of the upper layer circulation in the northern North Atlantic Ocean. J. Geophys. Res. 107, 3156, doi:10.1029/2001JC000901.

Bersch, M., Yashayaev, I. and Koltermann, K. P. 2007. Recent changes of the thermohaline circulation in the subpolar North Atlantic. Ocean Dynamics 57, 223-235.

Curry, R., Dickson, R. and Yashayaev, I. 2003. A change in the freshwater balance of the Atlantic Ocean over the past four decades. Nature 426, 826-829.

Dickson, R., Yashayaev, I., Meincke, J., Turrell, B., Dye, S. and Holfort, J. 2002. Rapid freshening of the deep North Atlantic Ocean over the past four decades. Nature 416, 832-837.

Draper, N. R. and Smith, H. 1998. Applied Regression Analysis, 3rd ed., Wiley-Interscience, New York, 706 pp.

Eldevik, T., Nilsen, J. E. Ø., Iovino, D., Olsson, K. A., Sandø, A. B. and Drange, H. 2009. Observed sources and variability of Nordic seas overflow. Nature Geoscience, doi:10.1038/ NGEO518.

Falina, A., Sarafanov, A. and Sokov, A. 2007. Variability and renewal of Labrador Sea Water in the Irminger Basin in 1991-2004. J. Geophys. Res. 112, C01006, doi:10.1029/2005JC003348.

Fogelqvist, E., Blindheim, J., Tanhua, T., Østerhus, S., Buch, E. and Rey, F. 2003. GreenlandScotland overflow studied by hydro-chemical multivariate analysis. Deep Sea Res., Part I 50, 73-102.

Gulev, S. K., Barnier, B., Knochel, H., Molines, J.-M. and Cottet, M. 2003. Water mass transformation in the North Atlantic and its impact on the meridional circulation: insights from on ocean model forced by NCEP/NCAR reanalysis surface fluxes. J. Clim. 16, 3085-3110.

Häkkinen, S. and Rhines, P. B. 2004. Decline of subpolar North Atlantic circulation during the 1990s. Science 304, 555-559.

Häkkinen, S. and Rhines, P. B. 2009. Shifting surface currents in the northern North Atlantic Ocean. J. Geophys. Res. 114, C04005, doi:10.1029/2008JC004883. 
484 Hátún, H., Sandø, A. B. and Drange, H. 2005. Influence of the Atlantic Subpolar Gyre on the thermohaline circulation. Science 309, 1841-1844.

Hawkins, E. and Sutton, R. 2008. Potential predictability of rapid changes in the Atlantic meridional overturning circulation. Geophys. Res. Lett. 35, L11603, doi:10.1029/ 2008GL034059.

Holfort, J. and Albrecht, T. 2007. Atmospheric forcing of salinity in the overflow of Denmark Strait. Ocean Sci. 3, 411-416.

Holliday, N. P., Hughes, S. L., Bacon, S., Beszczynska-Möller, A., Hansen, B. and co-authors. 2008. Reversal of the 1960s to 1990s freshening trend in the northeast North Atlantic and Nordic Seas. Geophys. Res. Lett. 35, L03614, doi:10.1029/2007GL032675.

Lazier, J., Hendry, R., Clarke, A., Yashayaev, I. and Rhines, P. 2002. Convection and restratification in the Labrador Sea, 1990-2000. Deep Sea Res. 49, 1819-1835.

Lozier, M. S. and Stewart, N. M. 2008. On the temporally-varying northward penetration of Mediterranean Overflow Water and eastward penetration of Labrador Sea Water. J. Phys.

Lozier, M. S., Leadbetter, S., Williams, R. G., Roussenov, V., Reed, M. S. C. and Moore N. J. 2008. The spatial pattern and mechanisms of heat-content change in the North Atlantic. Science 319, 800-803.

Peterson, B. J., McClelland, J., Curry, R., Holmes, R. M., Walsh, J. E. and Aagaard, K. 2006. Trajectory shifts in the Arctic and Subarctic fresh-water cycle. Science 313, 1061-1066.

Pickart, R. S., Spall, M., Ribergaard, M. H., Moore, G. W. K. and Milliff, R. 2003. Deep convection in the Irminger Sea forced by the Greenland tip jet. Nature 424, 152-156.

Sarafanov, A. 2009. On the effect of the North Atlantic Oscillation on temperature and salinity of the subpolar North Atlantic intermediate and deep waters. ICES J. Mar. Sci. 66, 1448-1454, doi:10.1093/icesjms/fsp094. 
509 Sarafanov, A., Sokov, A., Demidov, A. and Falina, A. 2007. Warming and salinification of 510 intermediate and deep waters in the Irminger Sea and Iceland Basin in 1997-2006. Geophys. Res. Lett. 34, L23609, doi:10.1029/2007GL031074.

Sarafanov, A., Falina, A., Sokov, A. and Demidov, A. 2008. Intense warming and salinification of intermediate waters of southern origin in the eastern subpolar North Atlantic in the 1990s to mid-2000s. J. Geophys. Res. 113, C12022, doi:10.1029/2008JC004975.

Sokov, A. V. 2007. Cruise 23 of RV “Akademik Ioffe”. cruise report, 86 pp., Shirshov Inst. of Oceanology, Moscow.

Scheinert, M., Böning, C. and Biastoch, A. 2008. Freshening of the subpolar North Atlantic: causes and consequences. Abstracts of the ICES International Symposium on Effects of climate change on the world's oceans, 4839, 69.

Thierry, V., de Boisséson, E., and Mercier, H. 2008. Interannual variability of the Subpolar Mode Water properties over the Reykjanes Ridge during 1990-2006. J. Geophys. Res. 113, C04016, doi:10.1029/2007JC004443.

Våge, K., Pickart, R. S., Thierry, V., Reverdin, G., Lee, C. M., Petrie, B., Agnew, T. A., Wong A. and Ribergaard, M. H. 2009. Surprising return of deep convection to the subpolar North Atlantic Ocean in winter 2007-2008. Nature Geoscience 2, 67-72, doi:10.1038/NGEO382.

van Aken, H. M. 2000. RV Pelagia shipboard report: cruise 64PE169, Project CLIVARNET Atlantic Monitoring Programme (CAMP). 21 pp., Netherlands Inst. for Sea Res., Texel.

van Aken, H. M. and de Boer, C. J. 1995. On the synoptic hydrography of intermediate and deep water masses in the Iceland Basin. Deep Sea Res. Part I. 42, 165-189.

Yashayaev, I. and Dickson, R. 2008. Transformation and fate of overflows in the Northern North Atlantic. In Arctic-Subarctic Ocean Fluxes, Eds. R. Dickson, J. Meincke, and P. Rhines, 505526, doi:10.1007/978-1-4020-6774-7_22.

Yashayaev, I. and Loder, J. W. 2009. Enhanced production of Labrador Sea Water in 2008. Geophys. Res. Lett. 36, L01606, doi:10.1029/2008GL036162. 
535 Yashayaev, I., van Aken, H. M., Holliday, N. P. and Bersch, M. 2007. Transformation of the 536 Labrador Sea Water in the subpolar North Atlantic. Geophys. Res. Lett. 34, L22605, 537 doi:10.1029/2007GL031812.

538 Yashayaev, I., Holliday, P., Bersch M. and van Aken, H. M. 2008. The history of Labrador Sea 539 Water: production, spreading, transformation and loss. In Arctic-Subarctic Ocean Fluxes, Eds. 540 R. Dickson, J. Meincke, and P. Rhines, 505-526, doi:10.1007/978-1-4020-6774-7_25. 
Figure 1. Locations of the World Ocean Circulation Experiment (WOCE) A1E/AR7E line (19911997, 'A1E'), the $59.5-60^{\circ} \mathrm{N}$ repeated section $\left(2002-2007\right.$, ' $60^{\circ} \mathrm{N}$ ') and the section occupied on board the RV Pelagia (2000, 'P-2000'). General pathways of the Nordic Seas overflow-derived deep waters - DSOW and ISOW - are schematically indicated. The deep water $\theta-\mathrm{S}$ changes discussed in the text are quantified in the Irminger Sea, where the sections are practically co-located.

Figure 2. Time series of (left) $\mathrm{S}$ and (right) $\theta\left({ }^{\circ} \mathrm{C}\right)$ anomalies for the DSOW (a, b) and ISOW (c, d) layers and for the entire deep water column (e, f) in the Irminger Sea. The linear regressions (19912007 for DSOW, 1992-2007 for ISOW and the entire deep water column) and cubic polynomial fits are shown with dashed and solid grey lines, respectively. $\mathrm{R}^{2}$ is the coefficient of determination (the squared correlation coefficient) indicating the proportion of variance in the time series accounted for by the polynomial model (Draper and Smith, 1998).

Figure 3. The 1991-2007 S anomalies for (a) DSOW and (b) ISOW plotted versus S anomalies for the entire deep water column. Axis scale is the same as in Figure 2. $\mathrm{R}^{2}$ is the squared Pearson's correlation coefficient; $\mathrm{p}$ is the probability that the correlation is due to chance.

Figure 4. (a) Salinity evolution in the interior Irminger Sea $\left(\sim 36-39^{\circ} \mathrm{W}\right.$, depths $\left.>3000 \mathrm{~m}\right)$ in $1991-$ 2007 as a function of potential density $\left(\sigma_{0}\right)$. (b) As in (a) but in anomalies normalized by their standard deviations at each level. Water mass density limits (see section 2) are indicated with dotted lines; 'LSW + ISOW' and 'ISOW + DSOW' denote the density classes of the water mass mixtures. Section occupations are marked with ticks on the top axis. Dashed curve in (b) represents the 561 smoothly interpolated timing of the lowest $\mathrm{S}$ anomalies ('S minimum') associated with transit of freshest (for the considered time period, 1991-2007) waters through the Irminger Sea interior. 
563 Figure 5. (a) Time series of the DSOW S anomalies in the Irminger Sea in 1963-2007 relative to

564 the long-term mean. Vertical axis scale is the same as in Figure 2. The linear regression for the 565 1983-2007 period and the 6th-order polynomial fit for the entire time period are shown with dashed 566 and solid grey lines, respectively. The time series is constructed from the 1963-2001 'WIS' (western 567 Irminger Sea) DSOW S values from D02 and the 2002-2007 DSOW S values derived from the $56860^{\circ} \mathrm{N}$ section data. (b) The DSOW S from this study plotted versus the 'WIS' DSOW S from D02 569 for the overlapping parts (1991-2000) of the time series. The line of equal values and the \pm 0.002 envelope, corresponding to the typical accuracy of the salinity data are shown. Coefficient of correlation of the two time series is 0.98 and the mean absolute difference is 0.002 .

Figure 6. Time series of $\mathrm{S}$ anomalies for the ISOW layer $\left(\sigma_{0}>27.86\right)$ in the Iceland Basin at $\sim 60^{\circ} \mathrm{N}$ in 1997-2007, updated from S07. Vertical axis scale is the same as in previous figures.

Figure 7. (left): The 1981-2001 time series of S anomalies for (a) the Faroe-Shetland overflow water, (b) LSW in the Iceland Basin, (c) entrainment - the 500-1000 m layer at the head of the Iceland Basin, (d) their 'mixture' (the sum of normalized S anomalies for each component: overflow + LSW + entrainment) and (e) ISOW observed east of the Reykjanes Ridge. The time series are based on the salinity values reported by D02 for the overflow, entrainment and ISOW and by Yashayaev et al. (2008) for LSW. The overflow, LSW and entrainment salinity anomalies are normalized with respect to the relative contribution of these waters to ISOW according to estimates by D02: $43 \%$ for the overflow, $26 \%$ for LSW and $31 \%$ for the entrainment. (right): ISOW S anomalies in 1990-2000 plotted versus normalized S anomalies for the ISOW components: (f) Faroe-Shetland overflow water, (g) LSW, (h) entrainment, (i) 'overflow + LSW + entrainment mixture' and (j) 'overflow + LSW mixture'. The 'overflow + LSW mixture' $S$ anomalies are calculated as the sum of normalized $\mathrm{S}$ anomalies for these two components. $\mathrm{S}$ anomaly axis scale is the same as in previous figures. $\mathrm{R}$ is the Pearson's correlation coefficient; $\mathrm{p}$ is the probability that the correlation is due to chance. 
588 Figure 8. The 1990-2000 S anomalies for (a) the 'entrainment' (normalized anomalies, see 589 Figure 7) and (b) ISOW in the Iceland Basin plotted versus the winter (December-March) NAO 590 index averaged for the 6 (a) and 8 (b) winters preceding the salinity measurements. S anomaly axis 591 scale is the same as in previous figures. 


\section{Figure 1}

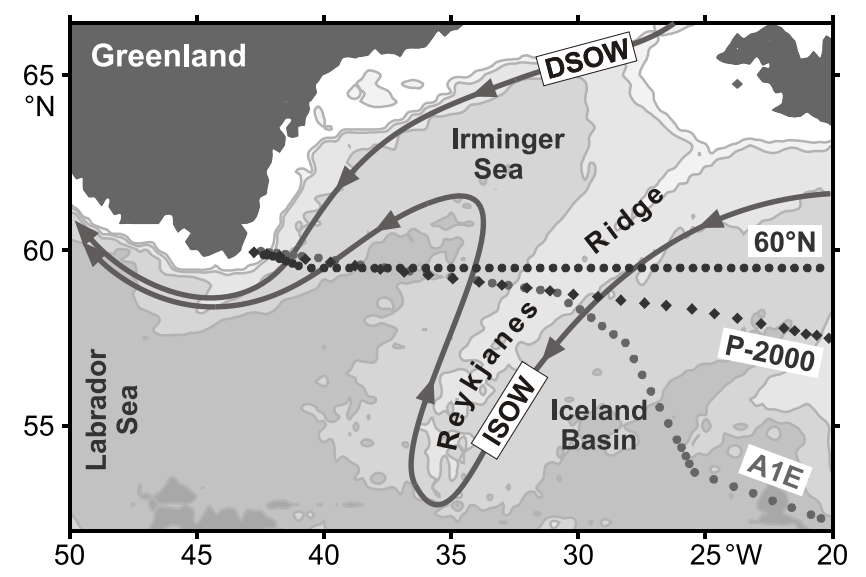

Figure 1. Locations of the World Ocean Circulation Experiment (WOCE) A1E/AR7E line (19911997, 'A1E'), the $59.5-60^{\circ} \mathrm{N}$ repeated section $\left(2002-2007\right.$, ' $60^{\circ} \mathrm{N}$ ') and the section occupied on board the RV Pelagia (2000, 'P-2000'). General pathways of the Nordic overflow-derived deep waters - DSOW and ISOW - are schematically indicated. The deep water $\theta-\mathrm{S}$ changes discussed in the text are quantified in the Irminger Sea, where the sections are practically co-located. 


\section{Figure 2}
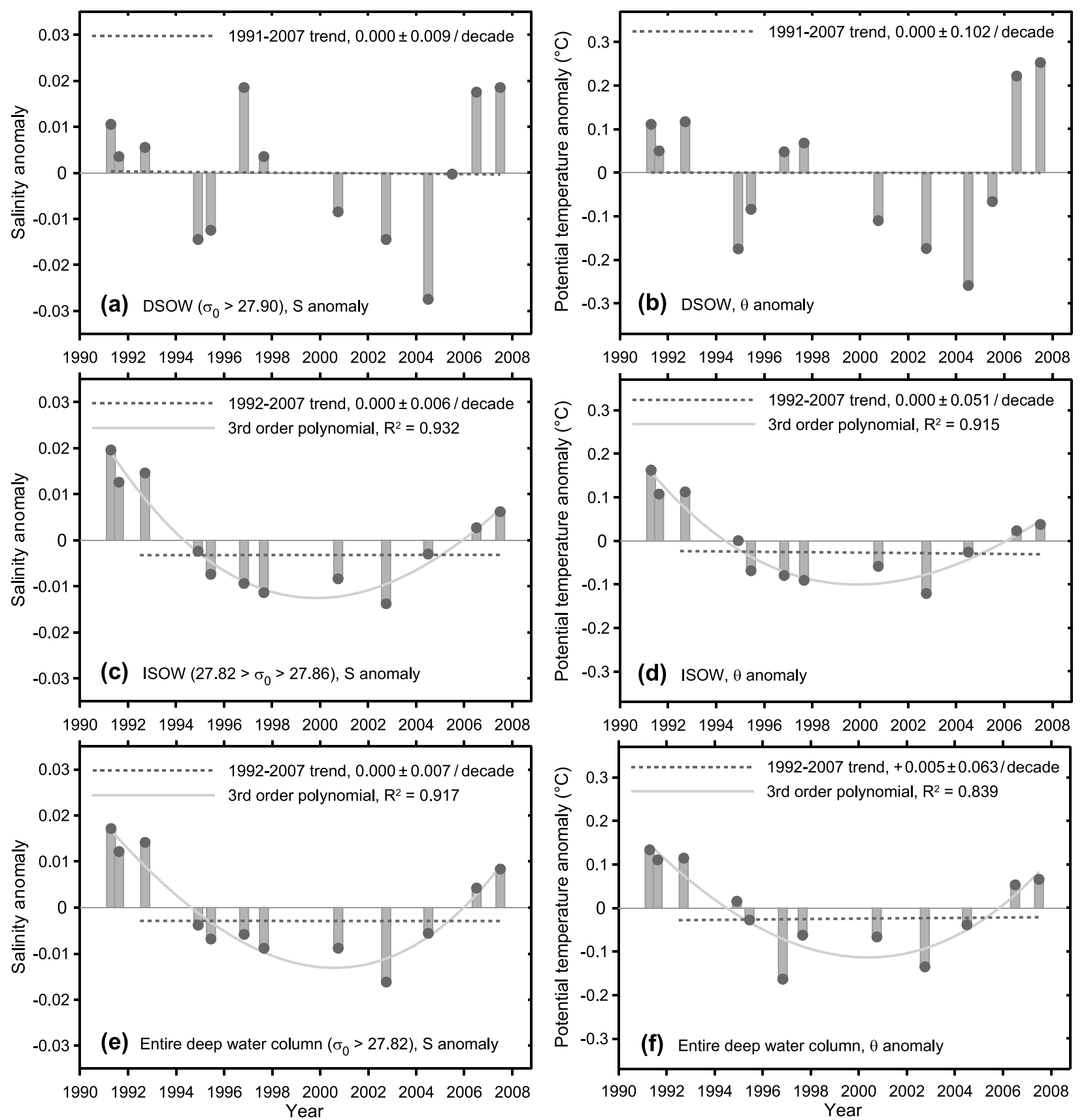

Figure 2. Time series of (left) $\mathrm{S}$ and (right) $\theta\left({ }^{\circ} \mathrm{C}\right)$ anomalies for the DSOW (a, b) and ISOW (c, d) layers and for the entire deep water column (e, f) in the Irminger Sea. The linear regressions (19912007 for DSOW, 1992-2007 for ISOW and the entire deep water column) and cubic polynomial fits are shown with dashed and solid grey lines, respectively. $\mathrm{R}^{2}$ is the coefficient of determination (the squared correlation coefficient) indicating the proportion of variance in the time series accounted for by the polynomial model (Draper and Smith, 1998). 


\section{Figure 3}
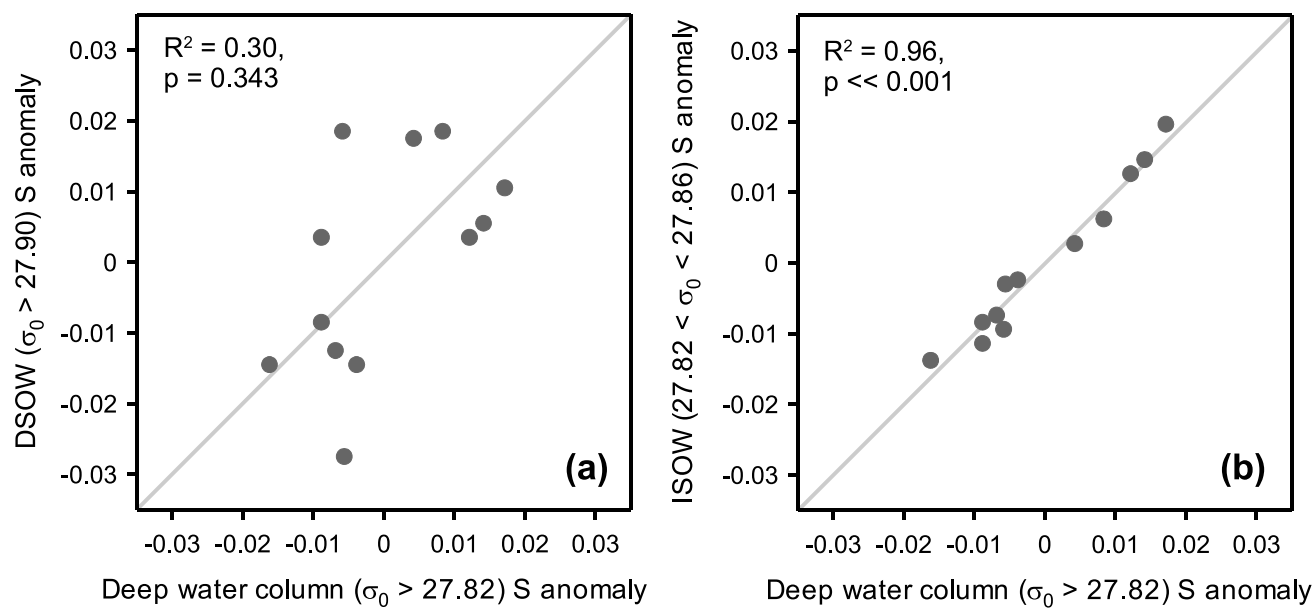

Figure 3. The 1991-2007 S anomalies for (a) DSOW and (b) ISOW plotted versus S anomalies for the entire deep water column. Axis scale is the same as in Figure $2 . \mathrm{R}^{2}$ is the squared Pearson's correlation coefficient; $p$ is the probability that the correlation is due to chance. 


\section{Figure 4}

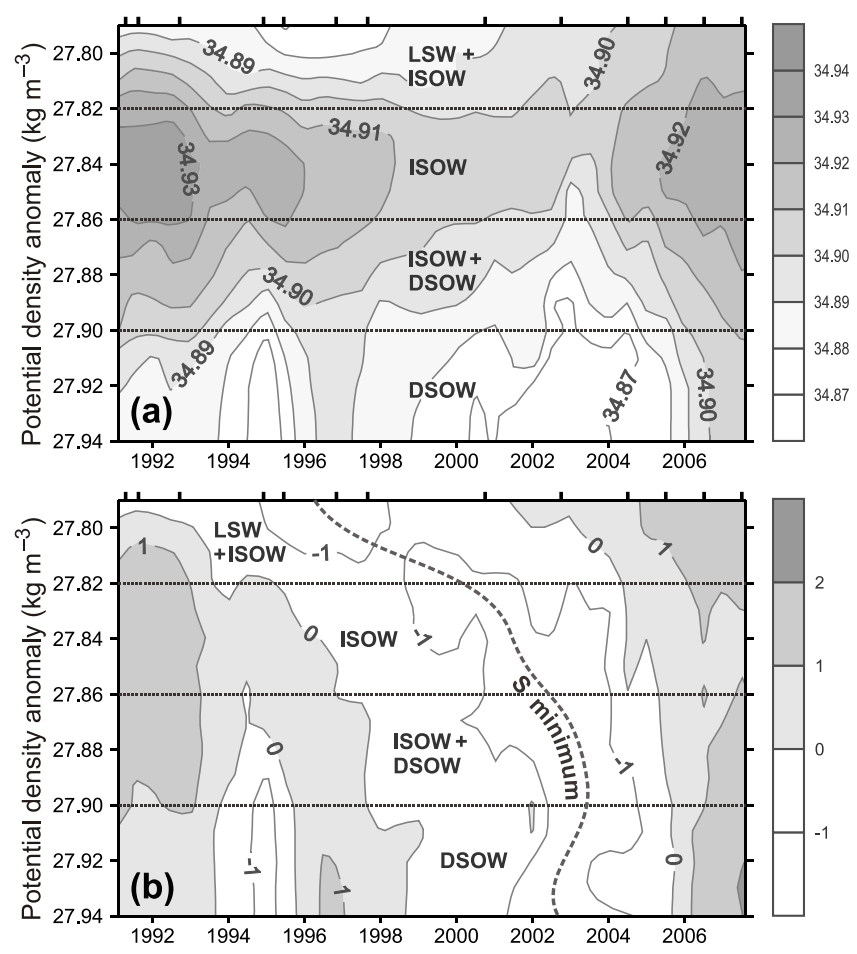

Figure 4. (a) Salinity evolution in the interior Irminger Sea $\left(\sim 36-39^{\circ} \mathrm{W}\right.$, depths $\left.>3000 \mathrm{~m}\right)$ in $1991-$ 2007 as a function of potential density $\left(\sigma_{0}\right)$. (b) As in (a) but in anomalies normalized by their standard deviations at each level. Water mass density limits (see section 2) are indicated with dotted lines; 'LSW + ISOW' and 'ISOW + DSOW' denote the density classes of the water mass mixtures. Section occupations are marked with ticks on the top axis. Dashed curve in (b) represents the smoothly interpolated timing of the lowest $\mathrm{S}$ anomalies ('S minimum') associated with transit of freshest (for the considered time period, 1991-2007) waters through the Irminger Sea interior. 


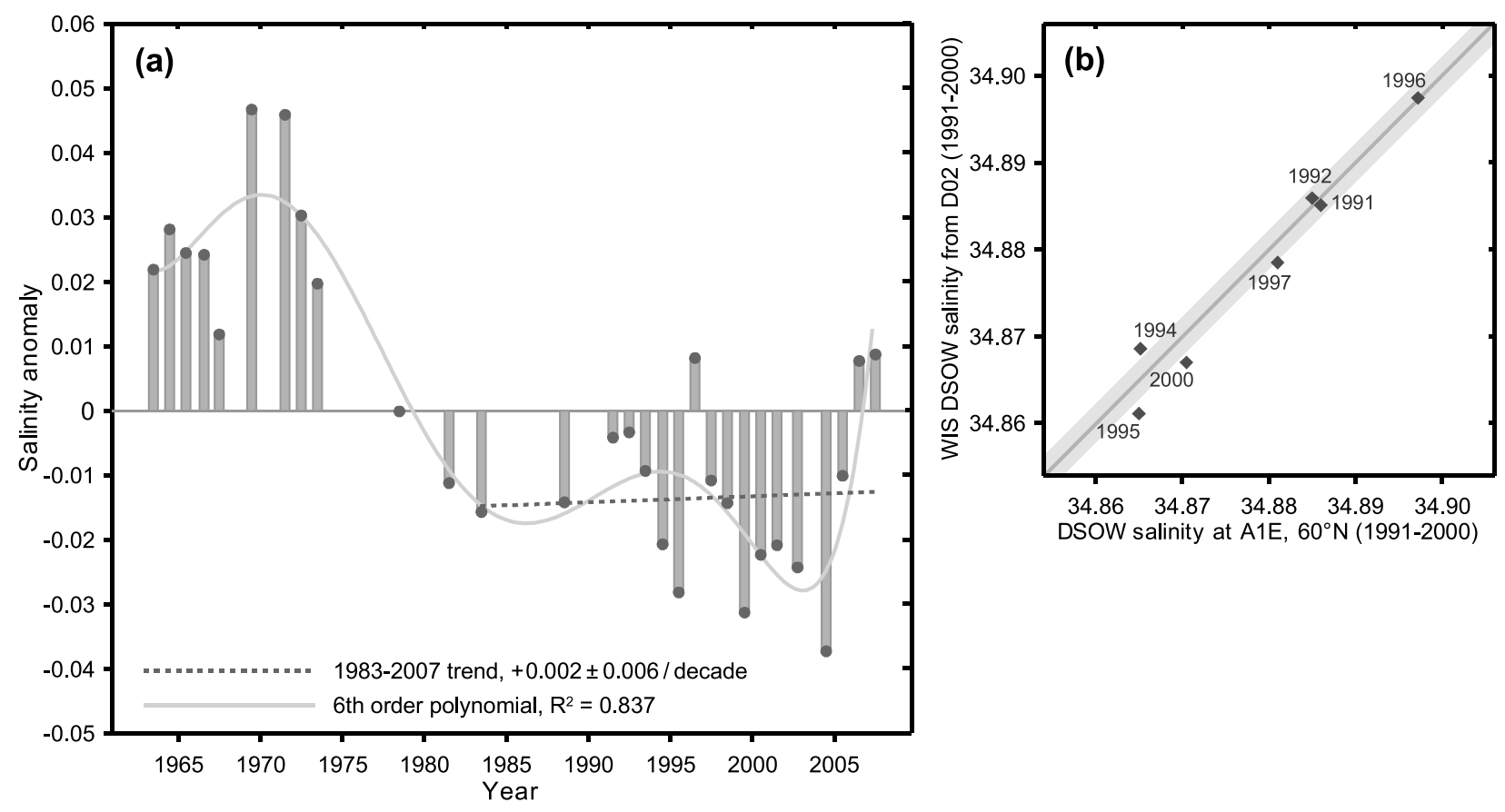

Figure 5. (a) Time series of the DSOW S anomalies in the Irminger Sea in 1963-2007 relative to the long-term mean. Vertical axis scale is the same as in Figure 2. The linear regression for the 1983-2007 period and the 6th-order polynomial fit for the entire time period are shown with dashed and solid grey lines, respectively. The time series is constructed from the 1963-2001 'WIS' (western Irminger Sea) DSOW S values from D02 and the 2002-2007 DSOW S values derived from the $60^{\circ} \mathrm{N}$ section data. (b) The DSOW S from this study plotted versus the 'WIS' DSOW S from D02 for the overlapping parts (1991-2000) of the time series. The line of equal values and the \pm 0.002 envelope, corresponding to the typical accuracy of the salinity data are shown. Coefficient of correlation of the two time series is 0.98 and the mean absolute difference is 0.002 . 


\section{Figure 6}

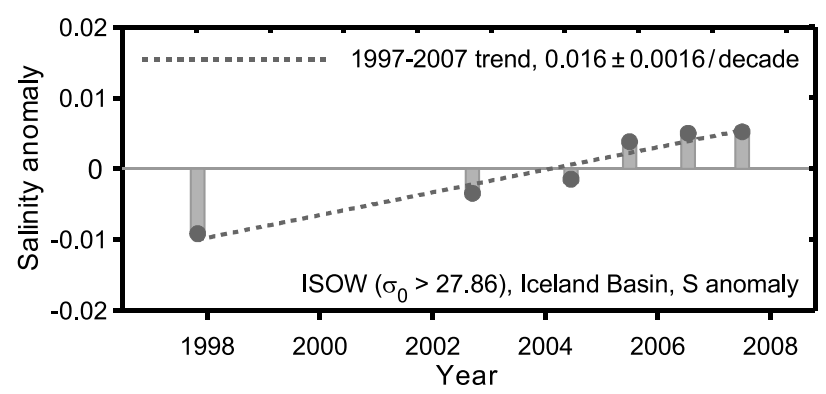

Figure 6. Time series of S anomalies for the ISOW layer $\left(\sigma_{0}>27.86\right)$ in the Iceland Basin at $\sim 60^{\circ} \mathrm{N}$ in 1997-2007, updated from S07. Vertical axis scale is the same as in previous figures. 

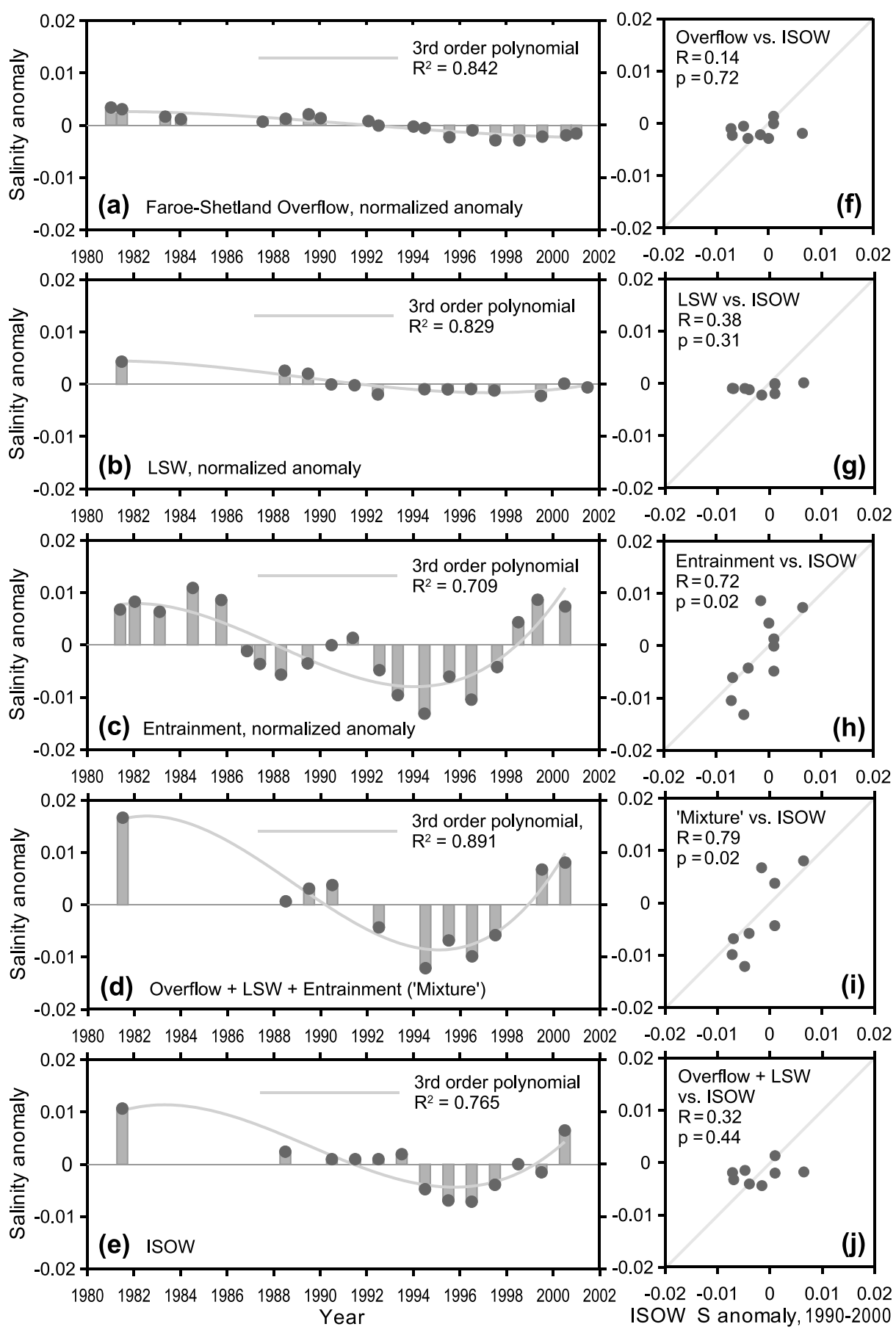

Figure 7. (left): The 1981-2001 time series of S anomalies for (a) the Faroe-Shetland overflow water, (b) LSW in the Iceland Basin, (c) entrainment - the 500-1000 m layer at the head of the Iceland Basin, (d) their 'mixture' (the sum of normalized $\mathrm{S}$ anomalies for each component: overflow + LSW + entrainment) and (e) ISOW observed east of the Reykjanes Ridge. The time series are based on the salinity values reported by D02 for the overflow, entrainment and ISOW and by Yashayaev et al. (2008) for LSW. The overflow, LSW and entrainment salinity anomalies are normalized with respect to the relative contribution of these waters to ISOW according to estimates by D02: $43 \%$ for the overflow, $26 \%$ for LSW and $31 \%$ for the entrainment. (right): ISOW S anomalies in 1990-2000 plotted versus normalized S anomalies for the ISOW components: (f) Faroe-Shetland overflow water, (g) LSW, (h) entrainment, (i) 'overflow + LSW + entrainment mixture' and (j) 'overflow + LSW mixture'. The 'overflow + LSW mixture' $S$ anomalies are calculated as the sum of normalized $\mathrm{S}$ anomalies for these two components. $\mathrm{S}$ anomaly axis scale is the same as in previous figures. $\mathrm{R}$ is the Pearson's correlation coefficient; $\mathrm{p}$ is the probability that the correlation is due to chance. 
Figure 8
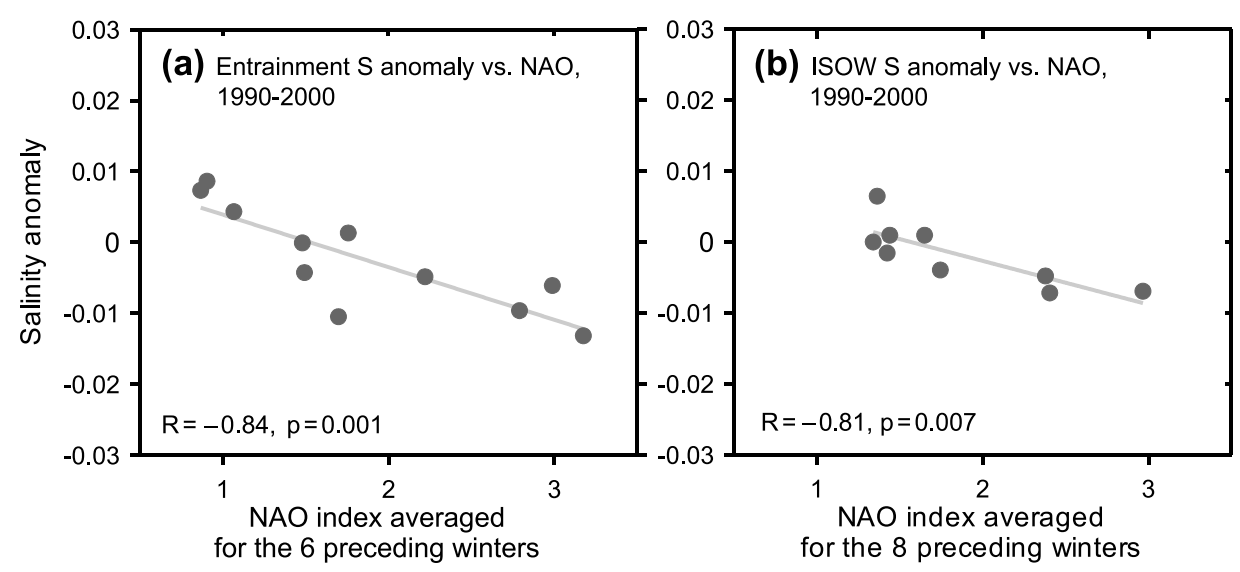

Figure 8. The 1990-2000 S anomalies for (a) the 'entrainment' (normalized anomalies, see Figure 7) and (b) ISOW in the Iceland Basin plotted versus the winter (December-March) NAO index averaged for the 6 (a) and 8 (b) winters preceding the salinity measurements. S anomaly axis scale is the same as in previous figures. 